\title{
Open or Closed? Technology Sharing, Supplier Investment, and Competition
}

\author{
Bin Hu, a Ming Hu, ${ }^{b}$ Yi Yangc, ${ }^{*}$ \\ a Kenan-Flagler Business School, University of North Carolina, Chapel Hill, North Carolina 27599; b Rotman School of Management, \\ University of Toronto, Toronto, Ontario M5S 3E6, Canada; ' School of Management, Zhejiang University, Hangzhou, Zhejiang 310027, China \\ *Corresponding author. \\ Contact: bin_hu@unc.edu (BH); Ming.Hu@rotman.utoronto.ca (MH); yangyizju@zju.edu.cn (YY)
}

Received: November 17, 2015

Revised: March 27, 2016; July 14, 2016

Accepted: July 18, 2016

Published Online in Articles in Advance: January 18, 2017

https://doi.org/10.1287/msom.2016.0598

Copyright: @ 2017 INFORMS

\begin{abstract}
Competing technologies in emerging industries create uncertainties that discourage supplier investments. Open technology can induce supplier investments, but may also lead to intensified future competition. In this paper, we study competing manufacturers' open-technology strategies. We show that despite the risk of intensifying future competition, open technologies by competing manufacturers may constitute an equilibrium and can indeed induce supplier investments. In addition, we identify a technology-riskpooling benefit; namely, by opening technologies, competing manufacturers can induce supplier investments in both technologies and later adopt the one preferred by the market. However, manufacturers may also exhibit the prisoner's dilemma and close their technologies despite the risk-pooling benefit. In this case, there is potential for collaborative technology sharing through cross licensing. Finally, we show that manufacturers may sometimes close their technologies to force supplier investments.

Funding: The first author is grateful for financial support from the Robert March and Mildred Borden Hanes Professorship. The second author is grateful for financial support from the Natural Sciences and Engineering Research Council of Canada [Grant RGPIN-2015-06757]. The third author is grateful for financial support from the National Natural Science Foundation of China [Grants 71201142 and 71522003] and the Key Project of China's National Social Science Fund [Grant 14ZDB137].

Supplemental Material: This paper has an e-companion at https://doi.org/10.1287/msom.2016.0598.
\end{abstract}

Keywords: open technology • technology choice • competitive strategy • supplier investment • procurement

\section{Introduction}

Many emerging industries exhibit tremendous potential, yet are hindered by the high costs of crucial components. An example is the alternative-energy vehicle industry. Between 2013 and 2014, U.S. electric vehicle sales grew by $69 \%$ (Ayre 2015a), but electric vehicles still have not grabbed a meaningful market share, one of the reasons being high costs (Perkowski 2014). For example, it was estimated that batteries alone in a Tesla Model S sedan cost around \$20,000 (Cole 2014) more than many economy cars. If battery suppliers made investments to reduce battery costs, electric vehicle sales may grow substantially, thereby benefiting the suppliers as well.

However, emerging industries are also often faced with competing technologies, which create uncertainties that discourage suppliers from making cost-reducing investments. In the alternative-energy vehicle industry, a competing technology to electric cars is hydrogen fuel cell cars. In 2014, Toyota launched its hydrogen fuel cell car Mirai, and Honda is set to follow soon. Like electric cars, hydrogen fuel cell cars are also expensive: the compact-sized, nonluxury Mirai carried a sticker price of $\$ 58,250$ in the United States (Gardner 2015). Comparing the two technologies, batteries and hydrogen fuel cells each have their pros and cons, ${ }^{1}$ and it is difficult to predict which technology will dominate the future alternative-energy vehicle industry.

Competing technologies put suppliers in difficult positions. Take Panasonic as an example. Panasonic is both a leading lithium-ion battery supplier (Deign 2015) and a pioneer in commercial hydrogen fuel cell applications (Watanabe 2015). What if Panasonic decided to make a major cost-reducing investment in lithium-ion batteries now, only to find in 10 years that the market prefers hydrogen fuel cell cars? This kind of risk may cause a supplier to wait out the technology uncertainty instead of making immediate cost-reducing investments, thereby slowing the entire industry's growth. The alternative-energy vehicle industry is by no means the only example; another case in point is the electrochemical energy storage industry, where the leading manufacturers are divided between using nickel-cadmium and lithium-ion batteries as energy storage media (Lyons 2013). The uncertain future market preference may similarly discourage battery suppliers from making heavy investments in either battery technology.

When suppliers hesitate to make investments in competing technologies, some firms adopt the strategy of open technology. In June 2014, Tesla Motors made a high-profile announcement that it would open 
its technology and "[would] not initiate patent lawsuits against anyone who, in good faith, wants to use [their] technology" (Musk 2014). In the announcement, Tesla's chief executive officer Elon Musk explained that "Tesla, other companies making electric cars, and the world would all benefit from a common, rapidly evolving technology platform," rallying the industry's confidence and investments in the open technology. Tesla's move might have created an advantage for the battery-car technology-briefly. Only several months later, Toyota also announced that it would open 5,680 patents on its fuel cell technology for free adoption by other automakers (Undercoffler 2015). The two firms clearly chose to open their competing technologies in a fight for the industry's favor and support. Intuitively, an open technology may better attract a supplier's investment because the technology may be adopted by competing firms, which translates into more demand for the supplier's product. However, it is unclear how exactly this reasoning will play out in a competitive environment where a competitor also has the option to open its technology, such as the case of Tesla and Toyota. For example, the aforementioned advantage of an open technology will disappear if the competing firm also opens its technology.

It is worth noting that open technology has a long history: since the Industrial Revolution, various industries including textiles, steel production, and personal computing have all benefited from open technologies (Bessen 2014). Nonetheless, history also teaches us another side of open technology. In the late 1970s, major personal computer manufacturers such as Apple and Atari used proprietary (closed) architectures, meaning that components produced for different systems were not compatible. When IBM entered the market with the Personal Computer (PC), it utilized an open architecture, such that anyone could make "IBM-compatible" computers (Miller 2011) effectively opening its architecture technology. This strategy greatly stimulated component suppliers to develop products for the PC (and PC-compatible computers), and IBM quickly became the market leader. However, once the PC proved successful, competitors soon flooded the market with PC-compatible computers, and IBM's market share dwindled to $5 \%$ before it sold the PC business to Lenovo (Spooner and Kanellos 2004). This case illustrates that while open technology can induce supplier investments, it may also lead to intensified future competition. Similarly, it is conceivable that Tesla and Toyota's recent decisions to open their technologies might intensify their future competition. For example, if the market later manifests a strong preference toward electric cars, Tesla's opentechnology strategy would make it easier for Toyota to switch to mass-producing electric cars.
The above discussion outlines the complex interplay of supplier investment and future competition induced by open technologies. In this paper, we aim to study whether competing firms will open their technologies considering such interplay. More specifically, we model two competing manufacturers; each one owns a proprietary technology, and each one may open his technology to the competitor. After the manufacturers announce their technology strategies, a supplier decides on whether to incur a fixed investment to obtain the ability to supply components for each technology. The market preference between the two technologies is then realized, after which each firm simultaneously chooses one technology to bring to the mass market. Finally, the supplier prices her component(s), and the two manufacturers either enjoy monopolies in their own markets with different technologies or compete head to head with the same technology. We model the technology strategies as decisions before the market preference is revealed to reflect the case of Tesla and Toyota where opentechnology decisions are made under uncertain market conditions to encourage supplier investments. On the other hand, to capture open technology's longterm risk of intensifying future competition if the technology proves successful, such as in the case of the IBM PC, we model the manufacturers' technology choices for their mass-market products as decisions after the market preference is revealed (see Section 3 for a more detailed discussion).

We use backward induction to fully characterize the four-stage (technology strategy, supplier investment, product technology choice, procurement) game and show that there is a unique subgame-perfect or trembling-hand-perfect equilibrium. Our results reveal a set of managerial insights (see Figure 1). First, we confirm our intuition that despite the risk of intensifying future competition, open technologies can indeed induce the supplier's cost-reducing investments when the required investment costs are high (the top region in Figure 1). This may partially explain the phenomenon of Tesla and Toyota opening their respective alternative-energy vehicle patents. In fact, Tesla later convinced Panasonic to invest $\$ 1$ billion in a joint venture (Rogowsky 2014), which was projected to drive down battery-pack-level costs by 70\% (Ayre 2015b). Second, we find that open technologies may yield a technology-risk-pooling benefit (the lower right region in Figure 1), namely, that by opening technologies, competing manufacturers can induce supplier investments in both technologies and later adopt the one preferred by the market. This benefit tends to materialize when the substitution between the technologies is strong. Third, the manufacturers may also face the prisoner's dilemma and close their technologies, 
Figure 1. Manufacturers' Equilibrium Technology Strategies

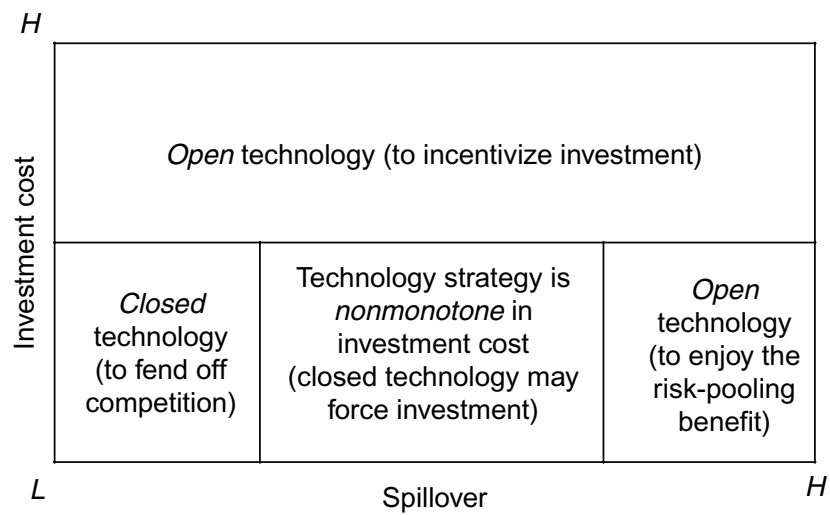

despite the risk-pooling benefit when both technologies are open (the lower left region in Figure 1). In this case, there is potential for collaborative technology sharing through cross licensing. Finally, somewhat surprisingly, when both the investment cost and the substitution between the technologies are in intermediate ranges, the manufacturers may close their technologies to force supplier investments in both technologies (the lower middle region in Figure 1), which means manufacturers may become less willing to open their technologies as investment costs increase.

We then investigate several model extensions that demonstrate the robustness of the base model's insights and also yield new insights. First, when the original technology owner has a first-mover advantage in the market, the base model's equilibrium structure largely remains. Second, asymmetric investment costs or market preferences can lead to different asymmetric equilibria. With low investment costs, the disadvantaged technology (in either investment cost or market preference) tends to be open to better compete with the advantaged technology for supplier investment, whereas with high investment costs, the advantaged technology tends to be open to induce the supplier's investment, while the disadvantaged technology becomes irrelevant. Third, when an alternative sourcing option exists, the focal supplier may be driven to invest more aggressively when the alternative source is expensive, but will give in and not make any investment if the alternative source is sufficiently cheap. Therefore, having an alternative sourcing option does not always stimulate supplier investments. Also, when the alternative sourcing option is affordable, asymmetric equilibria can arise between two completely symmetric manufacturers, where one opens his technology to attract the focal supplier's investment and the other closes his technology and depends on the alternative sourcing option.

In what follows, we review the related literature in Section 2, and introduce the base model in Section 3. The analysis and main results of the base model are presented in Section 4. We then discuss various extensions in Section 5 before concluding the paper and indicating potential future research directions in Section 6. All proofs are relegated to the online appendix.

\section{Literature Review}

Our paper is related to the literature on firms' technology strategies and their interactions with the firms' operational decisions. To the best of our knowledge, we are the first in the operations literature to consider firms' open-technology strategies, namely, one firm allowing competitors to use its proprietary technology. Various papers in this stream consider other types of technology strategies. Goyal and Netessine (2007) study multiproduct firms' flexible versus dedicated production technology choices in a competitive environment with uncertain demand. Open technology bears some resemblance to their flexible technology in the sense that both enable some pooling benefit but may also lead to intensified competition. However, the mechanisms behind them are completely different. In Goyal and Netessine (2007), each manufacturer decides on whether to allow capacity sharing across its own products, and thus capacity sharing is a centralized decision, whereas in our opentechnology problem, two manufacturers unilaterally decide on whether to open their respective technologies to competitors, and thus technology sharing is a decentralized outcome. Additionally, while open technology results in risk-pooling benefits similar to flexible capacity, its first-order effect is incentivizing the supplier's cost-reducing investments. Such vertical interactions across two supply chain tiers are absent in their paper. Along the same line of capacity flexibility, Boyabatli et al. (2015) study the trade-offs between flexible and dedicated technologies for a monopoly whose budget is constrained; Boyabatlı and Toktay (2011) consider relaxing this constraint by obtaining technology-specific loan contracts from a creditor; and Boyabatll (2015) further considers a third option in the flexible technology spectrum, fixed proportions technology, and identify its cost-pooling benefits. These papers similarly contrast with our paper in their centralized capacity sharing decisions versus our decentralized technology sharing competition. They also do not study horizontal interactions between competing manufacturers. We refer the reader to Boyabatli et al. (2015) for a more comprehensive, recent review of this stream of research.

Technology strategies other than gaining capacity flexibility have also been investigated. Debo et al. (2005) study the joint pricing and production technology decision by a firm introducing a remanufacturable product. The technology decision is modeled as a continuous remanufacturability level that influences the recoverable value from a used product. Krishnan and 
Bhattacharya (2002) explore the choice between a certain, proven technology and a superior prospective technology with uncertain viability. In a dynamic setting, Wang et al. (2013) study the environmental tradeoff between a conventional technology and a more costly new technology with a lower carbon footprint. None of these papers considers horizontal interactions (competition). A rare example of a model encompassing both vertical and horizontal interactions is by Erat and Kavadias (2006), who consider a technology provider that develops and sells two technologies over two periods to competing manufacturers. The technology introduced in the second period is an upgrade of the one introduced in the first period. This is of course a completely different problem from the one in this paper.

One may find our research problem of competing firms choosing to open versus close technologies similar to standard wars, such as those between VHS and Betamax, and between Blu-ray and highdefinition DVD. However, the two problems are fundamentally different. A standard is, by definition, open for adoption by any firm, but for a licensing fee. Therefore, standard wars occur between parties supporting already-open technologies. By contrast, in our problem the technologies are closed by default, and the manufacturers' decisions of whether to open their respective technologies are our very focus. Standard wars have been widely studied in economics; we refer the reader to Suarez (2004) for a recent review of the related literature.

Finally, our paper is related to the literature on the open-source movement in the software industry. Lerner and Tirole (2004) rationalize the growing opensource movement by using existing economic theories. Economides and Katsamakas (2006) and CasadesusMasanell and Ghemawat (2006) study the competition between a proprietary system (e.g., Windows) and an open-source system (e.g., Linux) in the presence of network externalities. Casadesus-Masanell and Llanes (2011) explore the mixed source model where some but not all modules are open source. While this literature deals with open versus closed technologies, most work there exclusively consider the consumer-side network effect. In other words, the emphasis is on how an open technology can attract more users because they anticipate more network benefits, compared to proprietary technologies (see Weber 2004). In our model, we deliberately exclude consumer-side network benefits to isolate open technologies' supply-side effect of incentivizing supplier investments, and by doing so prove that open technologies may be driven by supply-side network effects alone.

In summary, our work contributes to the study of open versus closed technologies in general by focusing on the supply side and bringing in operational considerations such as supplier investments and procurement interactions. We show that open technologies can incentivize supplier investments and provide riskpooling benefits; on the other hand, closed technologies may also force the supplier to make technology investments. These insights complement our existing knowledge about open technologies' consumer-side impacts.

\section{Base Model}

We consider two manufacturers $M_{1}$ and $M_{2}$ (he) endowed with proprietary, incompatible, and partially substitutable technologies 1 and $2\left(T_{1}\right.$ and $\left.T_{2}\right)$, respectively; e.g., Tesla and Toyota respectively utilizing batteries and hydrogen fuel cells to power their cars. Both technologies require key components from one supplier S (she); e.g., Panasonic. (In Section 5.4, we consider the case where there is an exogenous alternative sourcing option for the manufacturers.) The supplier has the fundamental technical know-how to supply key components for both technologies; e.g., producing batteries and fuel cells. However, the supplier's current production costs are prohibitively high, rendering these technologies nonviable for the mass market. Nonetheless, she can make a fixed investment $K$ to reduce the production cost for each component to an acceptable level (which we normalize to zero) and obtain the capability to economically supply the component; e.g., research and development for innovative manufacturing methods and/or constructing high-volume production facilities for batteries or fuel cells. We also allow $S$ to spend $2 K$ and obtain the capability to economically supply components for both technologies. It is worth noting that the required supplier investment $K$ does not depend on whether a technology is open or closed; for example, it would require the same amount of investment for Panasonic to reduce its battery cost, regardless of whether Tesla allows competitors to use its battery-based electric vehicle powertrain technology. The fixed $K$ is a simplification for tractability; in practice, a supplier will be able to choose the investment amount. However, investments and cost reductions typically do not have a linear relationship; an investment often needs to reach a critical threshold before it can substantially reduce production costs. In this sense, the fixed $K$ qualitatively captures this critical threshold.

We assume a unit-sized market, whose preference between the two technologies is initially uncertain. We model the market share that prefers technology 1 with a random variable $A \sim \operatorname{Uniform}[0,1]$; thus, the market share that prefers technology 2 is $1-A$. This setup reflects the technology uncertainties faced by manufacturers and suppliers in emerging industries; see Section 1. The manufacturers choose their technology strategies (open versus closed), and the supplier 
decides on which technology or technologies to invest in, before the market preference is realized. As is in the case of Tesla and Toyota, an open technology can be adopted by a competitor free of charge, whereas a closed technology cannot be adopted by competitors. On the other hand, to capture the fact that a manufacturer that opens his technology exposes himself to competitor entry if the technology proves successful, e.g., in the case of the IBM PC, we model the manufacturers' choices of technologies for their massmarket products, which take place after the market preference is realized. A more detailed remark on this point is offered later. If they introduce different technologies to the market, then each manufacturer will monopolize the market share that prefers his technology. On the other hand, if they introduce the same technology to the market (which can only happen if this is an open technology), a $\gamma$ fraction of the absent technology's market share will spill over into this technology's market share, in which the two manufacturers engage in Cournot competition. The parameter $\gamma$ therefore measures the substitutability between the two technologies. All agents are risk neutral and maximize their expected profits. The sequence of events is summarized as follows and illustrated in Figure 2:

Stage 1 (Ex ante manufacturer technology strategy). $M_{1}$ and $M_{2}$ simultaneously announce whether they will open their proprietary technologies. Once a technology is open, the competitor can adopt it free of charge; otherwise, the competitor cannot adopt it.

Stage 2 (Ex ante supplier investment). The supplier decides on whether to obtain the supply capabilities for the two technologies, each of which costs K. Once she obtains the supply capability for a technology, she can produce the components at (normalized) cost zero.

Stage 3 (Ex post manufacturer's technology choice). Once the market preference $A \sim$ Uniform $[0,1]$ is realized, $M_{1}$ and $M_{2}$ choose technologies for their products. If they adopt different technologies, then the market share that prefers each technology becomes its market size. On the other hand, if they adopt the same technology (only possible with an open technology), a $\gamma$ fraction of the absent technology's market share will spill over into this technology's own market share to form its market size. For example, if both manufacturers adopt technology 2 , then its market size is $(1-A)+\gamma A$.

Stage 4 (Ex post procurement game). After the manufacturers have chosen their technologies, a procurement game takes place. First, the supplier sets component wholesale price $w_{i}$ of each technology $i$ for which she has obtained the supply capability. The manufacturers then simultaneously decide on their order quantities for their chosen technologies. If they market different technologies, then each manufacturer enjoys a Cournot monopoly in his own technology's market share (i.e., market clearing price equals market size minus output). If they market the same technology, then they engage in Cournot duopoly competition (i.e., market clearing price equals market size minus total output) in this technology's market, where the market size contains the spillover from the absent technology's market share.

\subsection{Remarks on the Base Model}

Our base model captures the most salient elements of real-life manufacturers' open-technology considerations, including technology uncertainty, competitor response, supplier investment, and intensified competition after a technology proves popular. Below we offer some remarks on the base model.

- Simultaneous order quantity decisions. We assume that after choosing their technologies, $M_{1}$ and $M_{2}$ simultaneously determine their order quantities even when one of them adopts the competitor's open technology. This assumption may not be in line with the intuition that the original owner of a technology should have a head start over a late adopter in the market. However, this is not necessarily the case in many industries with long product development lead times. For example, Tesla's truly mass-market product, the Model 3 sedan, has been in planning for several years but is not expected to enter full production until 2018 (Edelstein 2015), four years after it opened its tech-

Figure 2. Sequence of Events

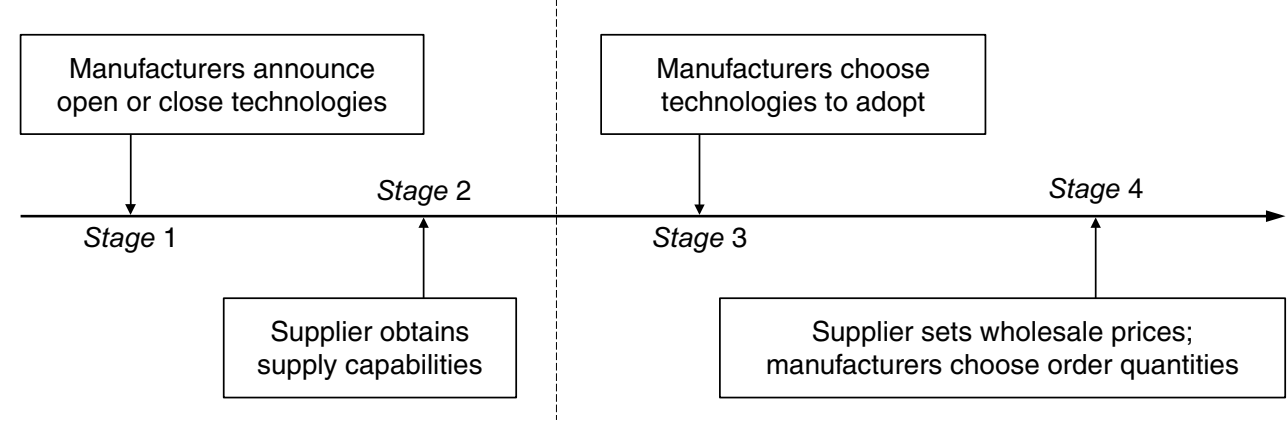

Market preferences are realized 
nology. Such long lead times mean that the original technology owner is not guaranteed a head start. Nevertheless, we still investigate sequential order quantity decisions in Section 5.1 and show that the base model's equilibrium structure largely remains.

- Symmetry. For simplicity, we consider symmetric technologies in the base model. We will explore asymmetric technologies in Sections 5.2 and 5.3, where we show that our main insights are robust and reveal new insights pertaining to asymmetric technologies.

- Exclusive supplier. The assumption that both manufacturers depend on one supplier for component supply is a clear simplification. In Section 5.4 we will consider an extension where an exogenous alternative source of supply exists and show that the manufacturers' behaviors do not change substantially.

- Ex post manufacturer technology choices. We assume that the manufacturers choose which technologies to bring to the market after the market preference is known. One may argue that in some cases firms introduce new technologies before the market preference is clear, but in such cases the sales volume tends to be limited. For instance, Toyota launched its hydrogen fuel cell car Mirai before learning the market preference, but the sales expectation was merely 200 units in the first year (Woodyard 2015). We instead focus on the manufacturers' technology choices for mass-market products, which usually take place after the market preference is revealed. For example, Hewlett-Packard used to produce business-oriented minicomputers, but entered the PC-compatible personal computer market after IBM's PC success. Modeling the manufacturers' ex post mass-market technology choices is essential in capturing an open technology's long-term risk of intensifying future competition.

- Market model. For tractability, we utilize a simple market model. Despite the simplicity, it captures the features that are most essential to our research problem: (1) consumers have preferences between technologies; (2) consumers respond to pricing; (3) competition drives down the price; (4) supplier investments indirectly benefit consumers by reducing costs; and (5) the competing technologies are partial substitutes. The insights from our model are driven qualitatively by these features, rather than the specific form of the market model.

\section{Model Analysis}

The base model is a multistage game, and we aim to find the subgame-perfect Nash equilibrium. To solve the model, we first find the subgame equilibria of stages 2 to 4 (supplier investment, manufacturer technology choice, and procurement game) for all possible outcomes of stage 1 (manufacturer technology strategy). We then solve for the equilibrium of stage 1 based on these subgame equilibria.

\subsection{Stages 2 to 4: Supplier Investment, Manufacturer Technology Choice, and Procurement Game}

There are three possible outcomes of stage 1: both manufacturers open their technologies, one manufacturer opens his technology and the other does not, and both manufacturers close their technologies. We will analyze each outcome below. In what follows, to specify profits $\pi$, we use superscripts $C C, O C, C O$, and OO to denote that $M_{1}$ and $M_{2}$ have opened (O) or closed (C) their respective technologies, and subscripts $i, j$ to denote player $i$ in stage $j$, where $i$ can be $s$, $m 1$, or $m 2$ for the supplier, $M_{1}$, or $M_{2}$, respectively, and $j$ can be $1,2,3$, or 4 . For example, $\pi_{m 1,2}^{\mathrm{CO}}$ represents $M_{1}$ 's optimal profit in stage 2 , given that $M_{1}$ closes the technology and $M_{2}$ opens the technology. Let $w_{i}$ and $q_{i}$ denote the wholesale price and order quantity for $M_{i}$. While some notation is reused in different scenarios, the context should eliminate any ambiguity.

4.1.1. Scenario CC: Both Manufacturers Close Technologies. In this scenario, each manufacturer always stays within his technology's market share; thus, the supplier can decide her investment for each technology individually. For symmetry, she will invest in both technologies or neither. We derive the manufacturers' profits on the basis of the supplier's investment decisions.

Case 1: Supplier invests in neither technology. In this trivial case, every player receives zero profit: $\pi_{s, 2}^{\mathrm{CC}}=$ $\pi_{m 1,2}^{\mathrm{CC}}=\pi_{m 2,2}^{\mathrm{CC}}=0$. This is the situation that neither technology will be adopted by the mass consumer market.

Case 2: Supplier invests in both technologies. For symmetry, we only consider $M_{1}$. Given wholesale price $w_{1}$, $M_{1}$ 's profit in stage 4 is $\pi_{m 1,4}^{\mathrm{CC}}\left(q_{1}\right)=\left(A-q_{1}-w_{1}\right) q_{1}$, and the optimal order quantity $q_{1}^{*}$ is $\left(A-w_{1}\right) / 2$. The expressions for $M_{2}$ are similar, with $A$ replaced by $1-A$. Accordingly, the supplier's profit is $\pi_{s, 4}^{\mathrm{CC}}=$ $\left(A-w_{1}\right) w_{1} / 2+\left(1-A-w_{2}\right) w_{2} / 2$, and the optimal wholesale prices are $w_{1}^{*}=A / 2$ and $w_{2}^{*}=(1-A) / 2$. In stage 4 , the optimal profits for the supplier, $M_{1}$, and $M_{2}$ are, respectively, $\pi_{s, 4}^{\mathrm{CC}}=A^{2} / 8+(1-A)^{2} / 8, \pi_{m 1,4}^{\mathrm{CC}}=A^{2} / 16$, and $\pi_{m 2,4}^{\mathrm{CC}}=(1-A)^{2} / 16$. Since $M_{1}{ }^{\prime} \mathrm{s}$ and $M_{2}{ }^{\prime}$ s profits are positive, in stage $3, M_{1}$ and $M_{2}$ will both introduce their technologies to the market if the supplier obtains supply capabilities in stage 2 . Finally, in stage 2, the supplier's expected profit from investing in both technologies is $\pi_{s, 2}^{\mathrm{CC}}=\mathbb{E}_{A}\left[\pi_{s, 4}^{\mathrm{CC}}\right]-2 K=1 / 12-2 K$. Therefore, the supplier invests in both technologies if $K<1 / 24$ (the supplier's expected profit from investing in a closed technology); otherwise, she invests in none, which is formalized in the following proposition.

Proposition 1 (Scenario CC). When both manufacturers close their technologies,

(i) if $K \geq 1 / 24$, the supplier invests in neither technology, and $\pi_{s, 2}^{\mathrm{CC}}=\pi_{m 1,2}^{\mathrm{CC}}=\pi_{m 2,2}^{\mathrm{CC}}=0$; 
(ii) if $K<1 / 24$, the supplier invests in both technologies, and $\pi_{s, 2}^{\mathrm{CC}}=1 / 12-2 K, \pi_{m 1,2}^{\mathrm{CC}}=\pi_{m 2,2}^{\mathrm{CC}}=1 / 48$.

4.1.2. Scenarios OC, CO: Only One Manufacturer Opens His Technology. For symmetry, it suffices to consider scenario OC, where only $M_{1}$ opens the technology. We derive the firms' profits on the basis of the supplier's investment decisions.

Case 1: Supplier invests in neither technology. In this trivial case, every player receives zero profit: $\pi_{s, 2}^{\mathrm{OC}}=$ $\pi_{m 1,2}^{\mathrm{OC}}=\pi_{m 2,2}^{\mathrm{OC}}=0$.

Case 2: Supplier invests in only one technology. In this case, the supplier chooses between investing in $T_{1}$ and $T_{2}$. When she invests in $T_{1}, M_{2}$ will adopt $T_{1}$, leading to some market expansion but also competition in the market, which benefits the supplier compared with when she invests in the closed $T_{2}$ and forces $M_{1}$ out of the market. This observation is generally true for the base model and can be formalized into the following lemma.

Lemma 1. When the supplier invests in only one technology, she invests in an open technology.

When the supplier invests in $T_{1}$, her market size becomes $\hat{A} \equiv A+\gamma(1-A)=\gamma+(1-\gamma) A$ due to spillover. In stage 4 , given wholesale price $w_{1}, M_{1}$ and $M_{2}$ engage in Cournot competition with symmetric profit functions $\pi_{i, 4}^{\mathrm{OC}}=\left(\hat{A}-q_{1}-q_{2}-w_{1}\right) q_{i}, i=m 1, m 2$. The equilibrium order quantities are $q_{i, 4}^{\mathrm{OC}}=\left(\hat{A}-w_{1}\right) / 3, i=$ $m 1, m 2$, and the resulting supplier's profit is $\pi_{s, 4}^{\mathrm{OC}}=$ $2\left(\hat{A}-w_{1}\right) w_{1} / 3$. The supplier sets wholesale price $w_{1}$ to maximize her profit, leading to equilibrium order quantity $\hat{A} / 6$ for each manufacturer, and equilibrium profits $\pi_{s, 4}^{\mathrm{OC}}=\hat{A}^{2} / 6, \pi_{m 1,4}^{\mathrm{OC}}=\pi_{m 2,4}^{\mathrm{OC}}=\hat{A}^{2} / 36$. By taking expectations with respect to $A$, the firms' stage 2 expected profits are $\pi_{s, 2}^{\mathrm{OC}}=\left(1+\gamma+\gamma^{2}\right) / 18-K, \pi_{m 1,2}^{\mathrm{OC}}=$ $\pi_{m 2,2}^{\mathrm{OC}}=\left(1+\gamma+\gamma^{2}\right) / 108$.

Case 3: Supplier invests in both technologies. In this case, since $T_{1}$ is open and the supplier builds both supply capabilities, $M_{2}$ can adopt either $T_{1}$ or $T_{2}$ in stage 3 . Therefore, we analyze two subcases: (I) $M_{2}$ adopts $T_{1}$; (II) $M_{2}$ adopts $T_{2}$. This case captures the available technology flexibility for a manufacturer when his competitor opens a technology.

In subcase (I), $M_{1}$ and $M_{2}$ engage in Cournot competition in $T_{1}$ 's market, which has a total size of $\hat{A}$ due to spillover. The analysis is similar to that of case 2 , and the firms' stage 4 profits are $\pi_{s, 4}^{\mathrm{OC}}=\hat{A}^{2} / 6, \pi_{m 1,4}^{\mathrm{OC}}=$ $\pi_{m 2,4}^{\mathrm{OC}}=\hat{A}^{2} / 36$.

In subcase (II), $M_{1}$ and $M_{2}$ each monopolize the market, of sizes $A$ and $1-A$, respectively, for their own technology. The analysis is similar to that of scenario CC, and the firms' stage 4 profits are $\pi_{s, 4}^{\mathrm{OC}}=A^{2} / 8+$ $(1-A)^{2} / 8, \pi_{m 1,4}^{\mathrm{OC}}=A^{2} / 16, \pi_{m 2,4}^{\mathrm{OC}}=(1-A)^{2} / 16$.

By comparing the two subcases, it is straightforward to show that $M_{2}$ will adopt $T_{1}$ if and only if $\hat{A}^{2} / 36 \geq$
$(1-A)^{2} / 16 \Leftrightarrow A \geq(3-2 \gamma) /(5-2 \gamma)$, namely, when $T_{1}$ is sufficiently popular. We can then calculate the firms' stage 2 expected profits:

$$
\begin{aligned}
\pi_{s, 2}^{\mathrm{OC}=} & \int_{0}^{(3-2 \gamma) /(5-2 \gamma)} \frac{A^{2}+(1-A)^{2}}{8} \mathrm{~d} A \\
& +\int_{(3-2 \gamma) /(5-2 \gamma)}^{1} \frac{(A+\gamma(1-A))^{2}}{6} \mathrm{~d} A-2 K \\
= & \frac{1}{12}+\frac{37+40 \gamma-20 \gamma^{2}}{36(5-2 \gamma)^{3}}-2 K \\
\pi_{m 1,2}^{\mathrm{OC}}= & \int_{0}^{(3-2 \gamma) /(5-2 \gamma)} \frac{A^{2}}{16} \mathrm{~d} A \\
& +\int_{(3-2 \gamma) /(5-2 \gamma)}^{1} \frac{(A+\gamma(1-A))^{2}}{36} \mathrm{~d} A \\
= & \frac{1}{48}-\frac{49-46 \gamma}{216(5-2 \gamma)^{2}}, \\
\pi_{m 2,2}^{\mathrm{OC}}= & \int_{0}^{(3-2 \gamma) /(5-2 \gamma)} \frac{(1-A)^{2}}{16} \mathrm{~d} A \\
& +\int_{(3-2 \gamma) /(5-2 \gamma)}^{1} \frac{(A+\gamma(1-A))^{2}}{36} \mathrm{~d} A \\
= & \frac{1}{48}+\frac{4-\gamma}{27(5-2 \gamma)^{2}} .
\end{aligned}
$$

With all three cases analyzed, we can determine the supplier's optimal technology investment decision in stage 2. Define two thresholds for the supplier's investment cost:

$$
\begin{gathered}
\beta_{1}^{\mathrm{OC}}(\gamma) \equiv \frac{1+\gamma+\gamma^{2}}{18}, \\
\beta_{2}^{\mathrm{OC}}(\gamma) \equiv \frac{(3-2 \gamma)(3-\gamma)\left(4 \gamma^{3}-8 \gamma^{2}-11 \gamma+9\right)}{18(5-2 \gamma)^{3}} .
\end{gathered}
$$

Note that $\beta_{1}^{\mathrm{OC}}(\gamma) \geq \beta_{2}^{\mathrm{OC}}(\gamma)$ for all $\gamma \in[0,1]$. The following proposition characterizes the equilibrium in scenario OC (and by symmetry, CO, with the manufacturer indices swapped).

Proposition 2 (Scenario OC). When only $M_{1}$ opens technology,

(i) if $K \geq \beta_{1}^{\mathrm{OC}}(\gamma)$, the supplier invests in neither technology, and $\pi_{s, 2}^{\mathrm{OC}}=\pi_{m 1,2}^{\mathrm{OC}}=\pi_{m 2,2}^{\mathrm{OC}}=0$;

(ii) if $\beta_{2}^{\mathrm{OC}}(\gamma) \leq K<\beta_{1}^{\mathrm{OC}}(\gamma)$, the supplier invests in $T_{1}$, and $\pi_{s, 2}^{\mathrm{OC}}=\left(1+\gamma+\gamma^{2}\right) / 18-K, \pi_{m 1,2}^{\mathrm{OC}}=\pi_{m 2,2}^{\mathrm{OC}}=(1+$ $\left.\gamma+\gamma^{2}\right) / 108$

(iii) if $K<\beta_{2}^{\mathrm{OC}}(\gamma)$, the supplier invests in both technologies, and

$$
\begin{aligned}
\pi_{s, 2}^{\mathrm{OC}} & =\frac{1}{12}+\frac{37+40 \gamma-20 \gamma^{2}}{36(5-2 \gamma)^{3}}-2 K \\
\pi_{m 1,2}^{\mathrm{OC}} & =\frac{1}{48}-\frac{49-46 \gamma}{216(5-2 \gamma)^{2}} \\
\pi_{m 2,2}^{\mathrm{OC}} & =\frac{1}{48}+\frac{4-\gamma}{27(5-2 \gamma)^{2}} .
\end{aligned}
$$


One would expect that lower technology investment costs always encourage the supplier to invest in more technologies. It is interesting to note that the threshold of the investment cost for investing in both technologies, $\beta_{2}^{\mathrm{OC}}(\gamma)$, is not always positive, meaning that the supplier may never invest in both technologies. We define $\gamma^{\mathrm{OC}} \in[0,1]$ as the solution to $4 \gamma^{3}-8 \gamma^{2}-$ $11 \gamma+9=0$. It is easy to verify that $\gamma^{\mathrm{OC}} \in[1 / 2,1]$ and is unique, and that $\beta_{2}^{\mathrm{OC}}(\gamma)<0 \Leftrightarrow \gamma>\gamma^{\mathrm{OC}}$. This leads to the following corollary.

Corollary 1. When only one manufacturer opens his technology and $\gamma>\gamma^{\mathrm{OC}}$, the supplier will invest only in the open technology even if the investment cost is zero.

To understand this result, consider the following trade-off for the supplier's investment in only $T_{1}$, in addition to the obvious cost saving benefit. On the one hand, $M_{2}$ is forced to adopt $T_{1}$ and compete with $M_{1}$, leading to a higher component purchase volume, which benefits the supplier. On the other hand, $M_{2}$ must forgo $T_{2}$ 's market share-save for the $\gamma$ portion that spills over to $T_{1}$-and that hurts the supplier. Clearly, a larger $\gamma$ mitigates the latter effect and makes investing in only $T_{1}$ more favorable. When $\gamma$ is sufficiently large, the strategic motivation of inducing competition alone is enough for the supplier to give up $T_{2}$ - even when doing so does not save any investment cost. This insight highlights strategic implications of a supplier's technology investment decision on future market dynamics, which would in turn influence the manufacturers' technology strategies. Note that the above discussion does not apply when both technologies are closed, in which case the supplier cannot induce competition by investing in only one technology.

\subsubsection{Scenario OO: Both Manufacturers Open Their} Technologies. We derive the firms' profits on the basis of the supplier's investment decisions.

Case 1: Supplier invests in neither technology. In this trivial case, every firm receives zero profits: $\pi_{s, 2}^{\mathrm{OO}}=$ $\pi_{m 1,2}^{\mathrm{OO}}=\pi_{m 2,2}^{\mathrm{OO}}=0$.

Case 2: Supplier invests in only one technology. By symmetry, we can assume that the supplier invests in $T_{1}$.

The analysis is similar to that for scenario OC's case 2 , and the firms' stage 2 expected profits are $\pi_{s, 2}^{\mathrm{OO}}=$ $\left(1+\gamma+\gamma^{2}\right) / 18-K, \pi_{m 1,2}^{\mathrm{OO}}=\pi_{m 2,2}^{\mathrm{OO}}=\left(1+\gamma+\gamma^{2}\right) / 108$.
Case 3: Supplier invests in both technologies. In this case, both manufacturers can freely adopt any technology. The manufacturers' technology choice equilibria in stage 3 are shown in Table 1, which presents the manufacturers' profits given their technology choices.

The next proposition characterizes the equilibrium of stage 3's manufacturer technology-choice game. Technically, multiple equilibria may arise, but we select one equilibrium following intuitive rules, which we will note after the proposition.

Proposition 3 (Equilibria with Two Open Technologies). When both manufacturers open their technologies and the supplier invests in both technologies, consider the stage 3 manufacturer technology choice game:

(i) if $\gamma \leq 1 / 2$, the Nash equilibrium is

$$
\begin{cases}\left(T_{1}, T_{1}\right) & \text { if } A \geq(3-2 \gamma) /(5-2 \gamma), \\ \left(T_{1}, T_{2}\right) & \text { if } 2 /(5-2 \gamma)<A<(3-2 \gamma) /(5-2 \gamma), \\ \left(T_{2}, T_{2}\right) & \text { if } A \leq 2 /(5-2 \gamma)\end{cases}
$$

(ii) if $\gamma>1 / 2$, the Nash equilibrium is

$$
\begin{cases}\left(T_{1}, T_{1}\right) & \text { if } A \geq 1 / 2 \\ \left(T_{2}, T_{2}\right) & \text { if } A<1 / 2\end{cases}
$$

Remark on Proposition 3 (Equilibrium Refinement).Technically, multiple Nash equilibria arise in both subcases. In subcase (i), when $\left(T_{1}, T_{2}\right)$ is an equilibrium, so is $\left(T_{2}, T_{1}\right)$, in which $M_{1}$ and $M_{2}$ swap technologies and payoffs. Two manufacturers adopting each other's technology despite having their own is clearly not a realistic scenario; thus, we rule out this equilibrium. In subcase (ii), $\left(T_{1}, T_{1}\right)$ and $\left(T_{2}, T_{2}\right)$ may both be equilibria; however, one always Pareto dominates the other. After the dominated equilibrium is ruled out, Proposition 3(ii) ensues.

The most important observation about Proposition 3 is that both manufacturers will adopt a technology if it turns out to be highly favorable. (This includes the cases when $A$ is either sufficiently large or small.) Although this observation itself is intuitive, it has a less straightforward implication: when both technologies are open and available, all parties benefit from technology risk pooling because the manufacturers can wait until the market preference becomes clear and adopt

Table 1. Payoff Matrix for the Manufacturers' Technology Choices in Scenario OO

\begin{tabular}{lccc}
\hline & & \multicolumn{3}{c}{$M_{2}{ }^{\prime}$ s choice } \\
\cline { 3 - 4 }$\pi_{m 1,3}^{\mathrm{OO}}, \pi_{m 2,3}^{\mathrm{OO}}$ & $T_{1}$ & $T_{2}$ \\
\hline$M_{1}{ }^{\prime}$ 's choice & $T_{1}$ & $\frac{(A+\gamma(1-A))^{2}}{36}, \frac{(A+\gamma(1-A))^{2}}{36}$ & $\frac{A^{2}}{16}, \frac{(1-A)^{2}}{16}$ \\
& $T_{2}$ & $\frac{(1-A)^{2}}{16}, \frac{A^{2}}{16}$ & $\frac{(1-A+\gamma A)^{2}}{36}, \frac{(1-A+\gamma A)^{2}}{36}$ \\
\hline
\end{tabular}


the more favorable technology. Note that this risk pooling benefit is not fully available if one technology is closed or if the supplier does not invest in both technologies. Therefore, it might drive manufacturers to open their technology as well as induce the supplier to invest in both technologies-even if eventually only one technology will be adopted. On the other hand, with $A$ in an intermediate range (i.e., neither technology dominates the other) and a low spillover factor, the manufacturers introduce their technologies in their own markets to avoid competition.

Using the equilibria in stage 3 , we can then calculate the firms' expected profits in stage 2:

(i) if $\gamma \leq 1 / 2$,

$$
\begin{aligned}
\pi_{s, 2}^{\mathrm{OO}}= & \int_{0}^{2 /(5-2 \gamma)} \frac{(1-A+\gamma A)^{2}}{6} \mathrm{~d} A \\
& +\int_{2 /(5-2 \gamma)}^{(3-2 \gamma) /(5-2 \gamma)} \frac{A^{2}+(1-A)^{2}}{8} \mathrm{~d} A \\
& +\int_{(3-2 \gamma) /(5-2 \gamma)}^{1} \frac{(A+\gamma(1-A))^{2}}{6} \mathrm{~d} A-2 K \\
= & \frac{1}{12}+\frac{37+40 \gamma-20 \gamma^{2}}{18(5-2 \gamma)^{3}}-2 K \\
\pi_{m 1,2}^{\mathrm{OO}}= & \pi_{m 2,2}^{\mathrm{OO}}=\int_{0}^{2 /(5-2 \gamma)} \frac{(1-A+\gamma A)^{2}}{36} \mathrm{~d} A \\
& +\int_{2 /(5-2 \gamma)}^{(3-2 \gamma) /(5-2 \gamma)} \frac{A^{2}}{16} \mathrm{~d} A \\
& +\int_{(3-2 \gamma) /(5-2 \gamma)}^{1} \frac{(A+\gamma(1-A))^{2}}{36} \mathrm{~d} A \\
= & \frac{1}{48}+\frac{38 \gamma-17}{216(5-2 \gamma)^{2}} ;
\end{aligned}
$$

(ii) if $\gamma>1 / 2$,

$$
\begin{aligned}
\pi_{s, 2}^{\mathrm{OO}=} & \int_{0}^{1 / 2} \frac{(1-A+\gamma A)^{2}}{6} \mathrm{~d} A \\
& +\int_{1 / 2}^{1} \frac{(A+\gamma(1-A))^{2}}{6} \mathrm{~d} A-2 K \\
= & \frac{7+4 \gamma+\gamma^{2}}{72}-2 K, \\
\pi_{m 1,2}^{\mathrm{OO}}= & \pi_{m 2,2}^{\mathrm{OO}}=\int_{0}^{1 / 2} \frac{(1-A+\gamma A)^{2}}{36} \mathrm{~d} A \\
& +\int_{1 / 2}^{1} \frac{(A+\gamma(1-A))^{2}}{36} \mathrm{~d} A=\frac{7+4 \gamma+\gamma^{2}}{432} .
\end{aligned}
$$

With all three cases analyzed, we can determine the supplier's optimal decision on technology investment in stage 2. Define three thresholds for this purpose on the supplier's investment cost:

$$
\begin{aligned}
& \beta_{1}^{\mathrm{OO}}(\gamma) \equiv \frac{1+\gamma+\gamma^{2}}{18}, \\
& \beta_{2}^{\mathrm{OO}}(\gamma) \equiv \frac{74+80 \gamma-40 \gamma^{2}-(5-2 \gamma)^{3}\left(-1+2 \gamma+2 \gamma^{2}\right)}{36(5-2 \gamma)^{3}}, \\
& \beta_{3}^{\mathrm{OO}}(\gamma) \equiv \frac{1-\gamma^{2}}{24} .
\end{aligned}
$$

Note that $\beta_{1}^{\mathrm{OO}}(\gamma) \geq \max \left\{\beta_{2}^{\mathrm{OO}}(\gamma), \beta_{3}^{\mathrm{OO}}(\gamma)\right\}, \beta_{2}^{\mathrm{OO}}(\gamma)>0$, and $\beta_{3}^{\mathrm{OO}}(\gamma) \geq 0$ for all $\gamma \in[0,1]$. It is interesting to observe that unlike Scenario OC, the supplier's revenue is always larger when investing in two technologies than in just one. For simplicity of notation, we further define

$$
\hat{\beta}(\gamma) \equiv \begin{cases}\beta_{2}^{\mathrm{OO}}(\gamma) & \text { if } \gamma \leq 1 / 2, \\ \beta_{3}^{\mathrm{OO}}(\gamma) & \text { if } \gamma>1 / 2,\end{cases}
$$

which is continuous at $1 / 2$ and decreasing in $\gamma$. The following proposition characterizes the optimal and equilibrium outcomes in Scenario OO.

Proposition 4 (Scenario OO). When both manufacturers open their technologies,

(i) if $K \geq \beta_{1}^{\mathrm{OO}}(\gamma)$, the supplier invests in neither technology, and $\pi_{s, 2}^{\mathrm{OO}}=\pi_{m 1,2}^{\mathrm{OO}}=\pi_{m 2,2}^{\mathrm{OO}}=0$;

(ii) if $\hat{\beta}(\gamma) \leq K<\beta_{1}^{\mathrm{OO}}(\gamma)$, the supplier invests in only one technology, and $\pi_{s, 2}^{\mathrm{OO}}=\left(1+\gamma+\gamma^{2}\right) / 18-K, \pi_{m 1,2}^{\mathrm{OO}}=\pi_{m 2,2}^{\mathrm{OO}}=$ $\left(1+\gamma+\gamma^{2}\right) / 108$

(iii) if $K<\hat{\beta}(\gamma)$, the supplier invests in both technologies. When $\gamma \leq 1 / 2$,

$$
\begin{aligned}
\pi_{s, 2}^{\mathrm{OO}} & =\frac{1}{12}+\frac{37+40 \gamma-20 \gamma^{2}}{18(5-2 \gamma)^{3}}-2 K \\
\pi_{m 1,2}^{\mathrm{OO}} & =\pi_{m 2,2}^{\mathrm{OO}}=\frac{1}{48}+\frac{38 \gamma-17}{216(5-2 \gamma)^{2}}
\end{aligned}
$$

otherwise,

$$
\begin{gathered}
\pi_{s, 2}^{\mathrm{OO}}=\frac{7+4 \gamma+\gamma^{2}}{72}-2 K, \\
\pi_{m 1,2}^{\mathrm{OO}}=\pi_{m 2,2}^{\mathrm{OO}}=\frac{7+4 \gamma+\gamma^{2}}{432} .
\end{gathered}
$$

With both technologies open, it is intuitive that the lower the technology investment cost, the more technologies invested in by the supplier. However, for a fixed technology investment cost, as the substitution between technologies increases, the supplier may increase or decrease the number of supported technologies. On the one hand, when the investment cost is high enough, as the spillover factor increases, the supplier increases the number of technologies she supports from 0 to 1 . That is because the strong spillover allows the supplier to capture a sizable portion of the market by supporting an open technology regardless of the realized market preference, thus justifying the high investment cost. On the other hand, when the investment cost is low enough, as the spillover factor increases, the supplier lowers the number of supported technologies from 2 to 1 . In this case, stronger spillover means it is more beneficial for the supplier if both manufacturers adopt the same technology, which they may not do willingly. Therefore, with a strong enough spillover, the supplier may invest in only one technology to force both manufacturers to adopt the same 
Figure 3. Equilibrium Manufacturer Technology Strategies and Optimal Supplier Technology Investment

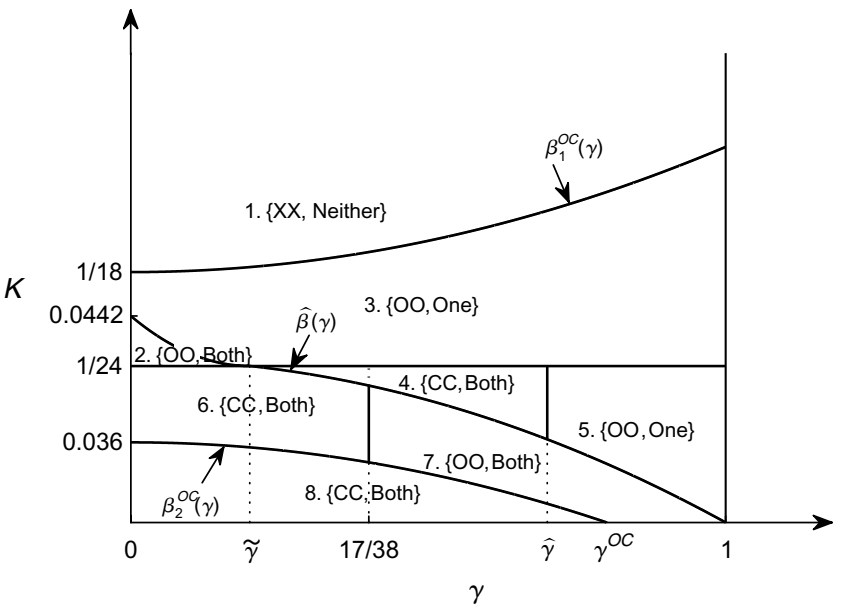

Notes. $\tilde{\gamma}$ is the solution in $[0,1]$ to the equation $\hat{\beta}(\gamma)=1 / 24, \hat{\gamma}=$ $(\sqrt{6}-1) / 2 \approx 0.725$, and $\gamma^{\mathrm{OC}}$ is the solution in $[0,1]$ to the equation $\beta_{2}^{\mathrm{OC}}(\gamma)=0$.

technology. (In anticipation of this behavior, manufacturers may in turn force the supplier to invest in both technologies by not opening their technologies; see Region 4 in Figure 3.)

\subsection{Stage 1: Manufacturer Technology Strategy}

With the stage $2-4$ subgames analyzed, we can finally characterize the stage 1 manufacturer technology strategy equilibrium and the ensuing stage 2 optimal technology investment decisions by the supplier. (See Figure 3 for an illustration of the outcomes; "OO" or "CC" means that both manufacturers open or close their technologies in equilibrium; "Neither," "One," or "Both" means that the supplier invests in neither, one, or both technologies as an optimal best response.)

In the stage 1 equilibrium analysis, we adopt the trembling-hand refinement. A Nash equilibrium survives the trembling-hand refinement if the equilibrium is sustained even when each player has a small probability of playing the off-equilibrium strategy. Such trembling captures possible errors in strategy executions and/or the risk of a player behaving nonrationally. This is a widely accepted refinement that ensures the equilibria to be robust in practice where not all players are necessarily fully rational and perfectly execute their strategies. In our model, a unique equilibrium survives this refinement. For convenience, we use "the unique perfect equilibrium" to represent either the unique subgame-perfect Nash equilibrium or the unique trembling-hand-perfect equilibrium. Moreover, for symmetry, when the supplier invests in one technology, she is indifferent between the two technologies; thus, we do not specify exactly which technology she invests in.

\subsubsection{High Investment Cost}

Theorem 1 (High Investment Cost: Open Technology Can Incentivize Investment). Suppose $K \geq 1 / 24$.

(i) If $K \geq \beta_{1}^{\mathrm{OC}}(\gamma)$, the supplier invests in neither technology, regardless of the manufacturers' technology strategies.

(ii) If $1 / 24 \leq K<\beta_{1}^{\mathrm{OC}}(\gamma)$, the unique perfect equilibrium of the stage 1 game is that both manufacturers open their technologies. The ensuing outcome in stage 2 is as follows:

(ii-1) if $\max \{1 / 24, \hat{\beta}(\gamma)\} \leq K<\beta_{1}^{\mathrm{OC}}(\gamma)$ (or equivalently, $\gamma$ is large enough), the supplier invests in only one technology;

(ii-2) if $1 / 24 \leq K<\max \{1 / 24, \hat{\beta}(\gamma)\}$ (or equivalently, $\gamma$ is small enough), the supplier invests in both technologies.

Theorem 1 characterizes the equilibrium behavior when investing in a technology costs more than the supplier's expected profit from doing so, i.e., $K \geq 1 / 24$. In case (i), where the technology investment cost is very high, the supplier never invests in any technology. This is a trivial case where all strategies are technically Nash equilibria, but these trivial equilibria have little practical value. In this case, technologies are not cost-efficient enough for commercial adoption. In Case (ii), because $K \geq 1 / 24$, the supplier would not invest in any technology if it were closed (see Proposition 1(i)). Therefore, both manufacturers open their technologies to incentivize supplier investment. Then, in subcase (ii-1), where spillover is relatively strong, the supplier invests in only one technology, because even when this technology turns out to be less popular, the supplier is still guaranteed a sizable market because of the strong spillover from the absent market. Thus, the supplier indirectly benefits from technology risk pooling and saves the high investment cost for one technology. In subcase (ii-2), where spillover is relatively weak, it is too risky to bet on a single technology, and thus the supplier invests in both technologies to take full advantage of the technology risk pooling (see the discussion following Proposition 3), which benefits the manufacturers as well.

When technology investment costs are too high for the supplier to invest in competing closed technologies, open technology can induce supplier investment. This insight from Theorem 1 confirms our intuition in the introduction. The case of Tesla's and Toyota's open technology "arms race" likely falls into this category. The automotive industry is highly capital intensive, and to boost industry confidence, both Tesla and Toyota chose to open their technologies. This might have been partially encouraged by Tesla's opentechnology strategy.

\subsubsection{Low Investment Cost}

Theorem 2 (Low Investment Cost and Weak Spillover: Closed Technology Fends Off Competition and May Encourage Investment). Suppose $K<1 / 24$ and $\gamma<17 / 38$. 
The unique equilibrium of the stage 1 game is that both manufacturers close their technologies. The ensuing stage 2 outcome is that the supplier invests in both technologies.

When investing in a technology costs less than the supplier's expected profit from doing so, and spillover is relatively weak, the equilibrium outcome is always that both manufacturers close their technologies and the supplier invests in both technologies. However, this equilibrium actually emerges for three different reasons, which result in different off-equilibrium outcomes.

First, when $K<\beta_{2}^{\mathrm{OC}}(\gamma)$ (i.e., the investment cost is very low), the supplier will invest in both technologies regardless of whether they are open or closed. Hence, the manufacturers do not need to incentivize supplier investments. The relatively weak spillover means that the potential market size for a popular technology (including the spillover from the other technology) is small. As a result, no manufacturer wants to unilaterally open his technology for fear of a small future market. Therefore, both manufacturers close their technologies in a Nash equilibrium.

Second, when $\beta_{2}^{\mathrm{OC}}(\gamma) \leq K<\hat{\beta}(\gamma)$ (i.e., the investment cost is in an intermediate range within $[0,1 / 24])$, the supplier will not invest in a technology if it is the only closed technology. In other words, if one technology is open and the other is closed, the supplier will invest only in the open technology. Again, the relatively weak spillover results in both manufacturers closing their technologies. As a result, the supplier has to invest in both technologies.

Third, when $\hat{\beta}(\gamma) \leq K<1 / 24$ (i.e., the investment cost is relatively high within $[0,1 / 24])$, the supplier will invest in only one open technology if at least one technology is open, and otherwise will invest in both technologies if spillover is not overly strong, i.e., $\gamma<\hat{\gamma}$ (where $\hat{\gamma}>17 / 38$ ). Thus, both manufacturers close their technologies to avoid being forced to compete in a market that is potentially small due to weak spillover; as a result, the supplier invests in both technologies. Since we have shown that open technologies can encourage supplier investment, the fact that closed technologies can also pressure the supplier to invest in more technologies (from one to two) is perhaps surprising and counterintuitive.

Theorem 3 (Low Investment Cost and Strong Spillover: Open Technology Can Generate Risk-Pooling Benefit). Consider $K<1 / 24$ and $\gamma \geq 17 / 38$.

(i) When $K<\beta_{2}^{\mathrm{OC}}(\gamma)$, the unique equilibrium of the stage 1 game is that both manufacturers close their technologies. In stage 2 , the supplier invests in both technologies.

(ii) When $\beta_{2}^{\mathrm{OC}}(\gamma) \leq K<\hat{\beta}(\gamma)$, the unique perfect equilibrium of the stage 1 game is that both manufacturers open their technologies. In stage 2, the supplier invests in both technologies. (iii) When $K \geq \hat{\beta}(\gamma)$, let $\hat{\gamma}=(\sqrt{6}-1) / 2 \approx 0.725$ :

(iii-1) If $\gamma<\hat{\gamma}$, the unique equilibrium of the stage 1 game is that both manufacturers close their technologies. In stage 2, the supplier invests in both technologies.

(iii-2) If $\gamma \geq \hat{\gamma}$, the unique perfect equilibrium of the stage 1 game is that both manufacturers open their technologies. In stage 2, the supplier invests in one technology.

In case (i) of Theorem 3, the equilibrium outcome is the same as in the first scenario discussed after Theorem 2. In this case, the manufacturers do not need to incentivize the supplier's technology investment, and the not-overly-strong spillover leads both manufacturers to close their technologies in a Nash equilibrium. However, unlike the case in Theorem 2 where the spillover is even weaker, in this case, if both manufacturers were to open their technologies, the supplier would invest in both technologies, and the manufacturers would be better off because of technology risk pooling. This is a classic prisoner's dilemma situation. ${ }^{2}$

To reiterate, with low technology investment costs and an intermediate level of spillover, manufacturers may be faced with the prisoner's dilemma and choose to close their technologies despite the full risk-pooling benefit enabled by two open technologies. It means that in such scenarios where firms will not unilateral open their technologies, there may be potential for collaborative technology sharing, such as cross licensing (i.e., an agreement between two parties to grant each other rights to their respective patents). In practice, cross licensing is fairly common; however, it usually serves as a means for firms to trade patents as well as to avoid or settle patent infringement disputes. In such applications, the patents being cross-licensed are often for unrelated technologies. Our result suggests that two firms may use cross licensing to allow each other access to competing technologies that serve fundamentally similar functions to enjoy technology risk pooling and avoid the prisoner's dilemma.

In case (ii) of Theorem 3, as in the second scenario discussed after Theorem 2, the supplier will not invest in a technology if it is the only closed technology. However, unlike that scenario with weak spillover, when spillover is not overly weak, all parties benefit from risk pooling when both manufacturers open their technologies. Since spillover is not very strong, the supplier has to invest in both technologies to benefit from full risk pooling. As a result, both manufacturers open their technologies, and the supplier invests in both technologies.

In case (iii) of Theorem 3, the supplier's incentive resembles the third scenario discussed after Theorem 2; namely, the supplier will invest in only one open technology if at least one technology is open. In subcase (iii-1), if spillover is not overly strong, i.e., $\gamma<\hat{\gamma}$, opening a technology may later lead to intense 
competition, and thus both manufacturers close their technologies. By contrast, in subcase (iii-2), the relatively strong spillover means that even a single open technology is guaranteed a sizable market and makes significant risk pooling possible. Therefore, both manufacturers open their technologies to benefit from risk pooling, and the supplier invests in only one technology to balance risk pooling and investment cost.

It can be seen that with an intermediate level of spillover, i.e., $17 / 38 \leq \gamma<\hat{\gamma}$, somewhat surprisingly, the equilibrium manufacturer technology strategy is nonmonotonic in the technology investment cost. More specifically, as the investment cost increases, the equilibrium behavior changes from $\{C C, B o t h\}$ to $\{\mathrm{OO}$, Both\}, and then back to \{CC, Both\}. The explanation is as follows. First, when the investment cost is low enough, the supplier will always invest in both technologies whether the manufacturers open or close their technologies. Although $\{\mathrm{OO}, \mathrm{Both}\}$ generates higher profits than $\{C C$, Both $\}$, manufacturers have an incentive to unilaterally close their technologies to deter competition. That is the prisoner's dilemma. Second, as the investment cost increases, the supplier will not invest in a technology if it is the only closed technology. As a result, both manufacturers open their technologies when spillover is not overly weak, and the supplier invests in both technologies. Third, as the investment cost rises further, the supplier will invest in only one open technology if at least one technology is open; otherwise, she will invest in both technologies if spillover is not overly strong. As mentioned, both manufacturers prefer closed technologies. The second scenario occurs when spillover is not overly weak, and the third scenario occurs when spillover is not overly strong. As a result, this nonmonotonic behavior is observed only with an intermediate level of spillover. The nonmonotonic equilibrium technology strategies also lead to all

Figure 4. Firms' Expected Profits

$$
\text { (a) } \gamma=\frac{1}{2}
$$

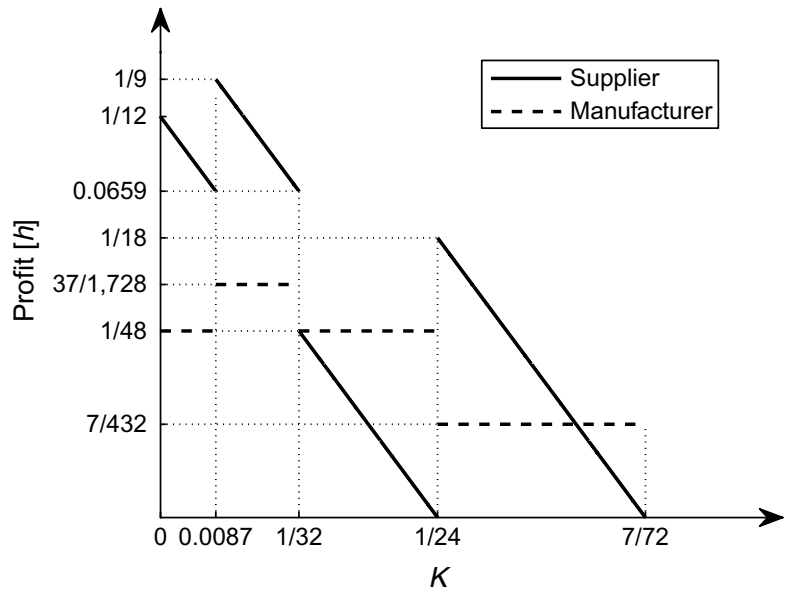

players' profits being nonmonotonic in the technology investment cost (see Figure 4(a)).

Another interesting observation is that manufacturers' expected profits are nonmonotonic in the spillover factor (see Figure 4(b)). On the one hand, when $\gamma \in[0,0.84]$, the manufacturers' expected profits are increasing in $\gamma$. The reason is that for low technology investment costs, when spillover becomes stronger, the manufacturers tend to shift from closing to opening their technologies to benefit from risk pooling. On the other hand, when $\gamma$ continues to increase, the supplier invests in fewer technologies-because one open technology already provides significant risk pooling for the supplier-and that causes the manufacturers' profits to drop. However, it can be observed that the supplier's profit is always increasing in $\gamma$.

Theorem 3 demonstrates that the spillover effect greatly influences competing firms' technology strategies, particularly with low technology investment costs. In general, stronger spillover tends to encourage open technologies for two reasons: first, stronger spillover better mitigates the detrimental effect of competition resulting from opening technologies; second, stronger spillover improves technology risk-pooling benefits.

4.2.3. Summary. Our analyses confirm the intuition that open technologies can encourage supplier investments. In addition, we present below a list of somewhat unexpected managerial insights. The numbered equilibrium cases in the summary are defined in Figure 3.

- When the investment cost and the demand spillover between technologies are in an intermediate range, manufacturers close their technology to force the supplier to invest in both technologies (equilibrium case 4$)$.

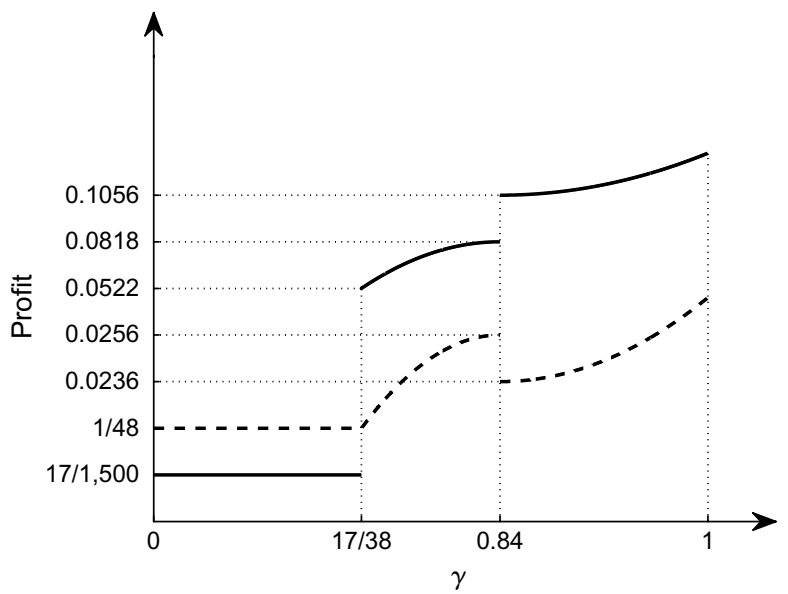


- Besides encouraging supplier investments, open technologies yield another benefit, namely, technology risk pooling. This benefit is realized with either high investment costs (as in equilibrium cases 2 and 3 ) or strong spillover (as in equilibrium cases 5 and 7), resulting in both manufacturers opening their technologies.

- With high technology investment costs or strong spillover, as the investment cost rises, the manufacturers tend to open their technologies to induce supplier investments. However, as they do so, the supplier may invest in fewer technologies due to the higher investment cost (see the change from equilibrium case 6 to 2 to 3 and from equilibrium case 8 to 7 to 5 when $\gamma \geq \hat{\gamma}$ ).

- With low technology investment costs and intermediate spillover, manufacturers may be faced with the prisoner's dilemma and close their technologies despite the benefits of technology risk pooling if both technologies are open (see equilibrium case 8,17/38< $\gamma<\hat{\gamma}$ ). In this case, there is potential for collaborative technology sharing, such as cross licensing.

- As the investment cost increases, manufacturers may become less willing to open their technologies (from equilibrium case 7 to case 4), and their equilibrium profits may increase (from equilibrium case 8 to case 7; see the first two segments of Figure 4(a)).

\section{Extensions}

Owing to the complexity of the problem, we utilize a simplified base model to flush out the fundamental insights. It is necessary to check whether these insights are robust when certain assumptions are relaxed or modified. In this section, we investigate three main extensions of the basic model: (1) sequential order quantity decisions; (2) asymmetric technologies; (3) alternative source of supply. While these extensions are mostly tractable, it is difficult to present full results because of their complexity. Therefore, we will present the most representative results.

\subsection{Sequential Order Quantity Decisions}

In Section 3, we discussed why $M_{1}$ and $M_{2}$ simultaneously determining order quantities after choosing their technologies is a more appropriate assumption for our motivating example (see Remarks on the Base Model). Nevertheless, sequential order quantity decisions may fit certain business cases better; hence, we investigate such a model. The comparison between sequential and simultaneous quantity competitions is well studied, and a key insight is that in sequential competition, the first mover has an advantage over the second mover (see Fellner 1949).

Specifically, we modify our base model so that when $M_{1}$ and $M_{2}$ adopt the same technology, the original technology owner determines his order quantity before the other manufacturer in stage 4 . Such a model captures business cases in which product development cycles are short and original technology owners have significant first-mover advantages. The detailed analysis can be found in Supplement $\mathrm{A}$ in the online appendix; we illustrate only the stages 1 and 2 equilibrium outcomes in Figure 5.

The foremost observation is that the equilibrium structure is largely consistent with the base model (see Figure 3). This shows that most of our main insights are robust under sequential order quantity decisions. There are a few other notable observations, which we discuss below. They are mostly driven by the fact that when both manufacturers adopt the same technology, sequential order quantity decisions increase the profits of the supplier and the technology owner, but reduce the other manufacturer's profit, due to an increased order quantity from the technology owner.

First, the region with the equilibrium $\{\mathrm{OO}$, One $\}$ expands against the $\{X X$, Neither $\}$ region. Under sequential order quantity decisions, the supplier earns more from an open technology; hence, there is a stronger incentive for the supplier to invest in an open technology.

Second, one may expect that there is more incentive for a manufacturer to open his technology, because when the competitor adopts his technology, the firstmover advantage improves his profit. However, surprisingly, the first-mover advantage may actually cause a manufacturer to close his technology when the investment cost and spillover are in an intermediate range. In such cases, the equilibrium is $\{C C$, Both\} under sequential order quantity decisions, in contrast with $\{\mathrm{OO}$, Both $\}$ under simultaneous order quantity decisions (equilibrium case 7 in Figure 3). The reason is that under sequential order quantity decisions,

Figure 5. Equilibrium Outcomes Under Sequential Order Quantity Decisions

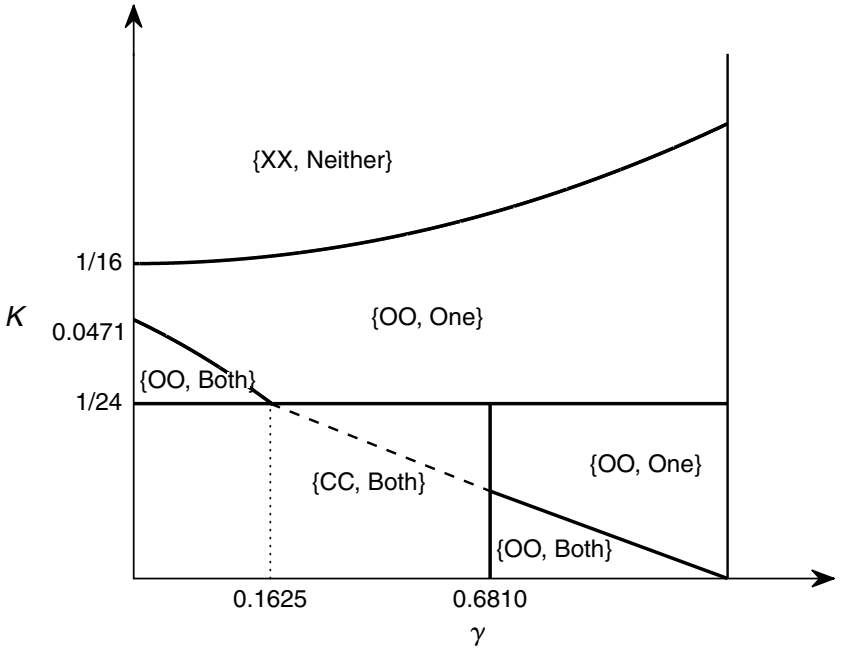


when both manufacturers adopt the same technology, the supplier's profit is also improved. As a result, in those cases, the supplier only invests in one technology when both technologies are open. In anticipation, both manufacturers close their technologies and force the supplier to invest in both technologies.

\subsection{Asymmetric Investment Costs}

In this section we investigate technologies that are asymmetric in investment cost. We denote the investment costs of technologies 1 and 2, respectively, by $K_{1}$ and $K_{2}$, and assume without loss of generality that $K_{1} \leq K_{2}$. The detailed analysis can be found in Supplement B in the online appendix; we illustrate only the stage 1 and 2 equilibrium outcomes with varying $K_{1}$ and $K_{2}$ for $\gamma=1 / 2$ in Figure 6, where " $X$ " indicates that either an open or a closed technology of the corresponding manufacturer can constitute an equilibrium, and $T_{i}$ denotes the technology that the supplier invests in. In addition, Figure S1 in Supplement B in the online appendix, illustrates equilibrium outcomes with other $\gamma$ values, which have similar structures as Figure 6.

We list some notable observations about Figure 6. First, on the line $K_{1}=K_{2}$, the equilibria replicate those in Figure 3 for $\gamma=1 / 2$. In the immediate neighborhood of $K_{1}=K_{2}$, the equilibria remain the same except near a single point $\left(K_{1}=1 / 24\right)$, where an asymmetric equilibrium arises. Therefore, the equilibria characterized for the symmetric base model are mostly robust under nottoo-significant technology investment cost asymmetry.

Second, with asymmetric investment costs, asymmetric equilibria may arise, and in most cases manufacturer 2 opens his technology. (In those scenarios with

Figure 6. Equilibrium Outcomes Under Asymmetric Fixed Costs $K_{1} \leq K_{2}$

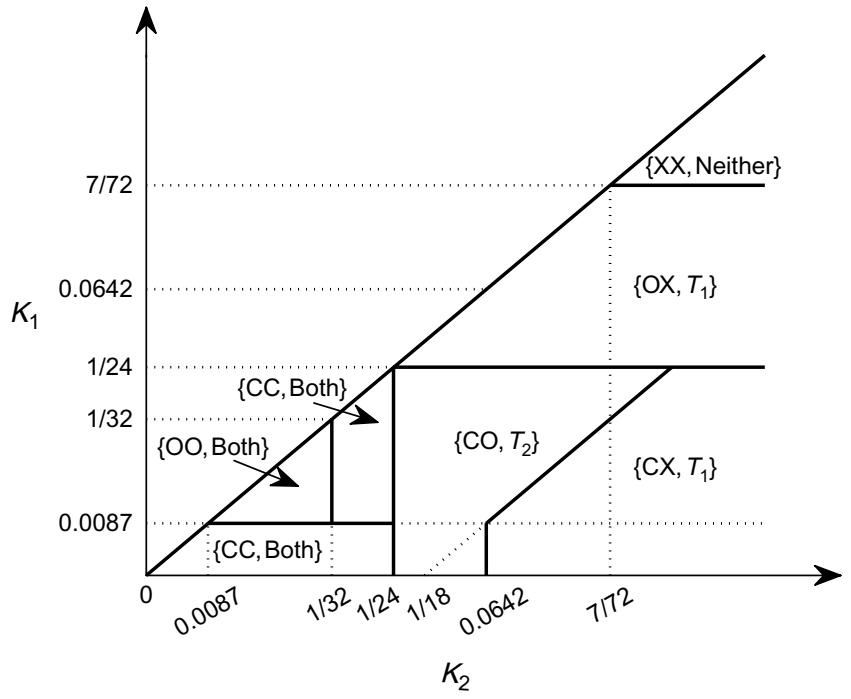

an asymmetric equilibrium, if there is only one equilibrium, it must be manufacturer 2 who opens his technology, and if there are multiple equilibria, there must exist an equilibrium in which manufacturer 2 opens his technology.) Recall that $K_{1} \leq K_{2}$; in other words, $T_{2}$ is the disadvantaged technology that requires a higher investment cost. The fact that the disadvantaged technology is more often open is intuitive: since the supplier is otherwise likely to invest in the advantaged technology, the manufacturer's only hope is to influence the supplier by opening his technology. This strategy is evident in the equilibrium $\left\{\mathrm{CO}, \mathrm{T}_{2}\right\}$, where the supplier invests in the more expensive but open technology 2. However, when the investment costs are highly asymmetric with $T_{2}$ being much more expensive, this strategy no longer works, as is evident in the equilibrium $\left\{C X, T_{1}\right\}$, where the supplier always invests in the less costly $T_{1}$ regardless of whether manufacturer 2 opens or closes his technology.

Third, interestingly enough, in one equilibrium scenario, $\left\{\mathrm{OX}, T_{1}\right\}$, it is the advantaged manufacturer $M_{1}$ who opens his technology. Note that this occurs with relatively high investment costs for both technologies. In this case, even the advantaged manufacturer needs to incentivize supplier investments, and the disadvantaged manufacturer's technology strategy becomes irrelevant.

\subsection{Asymmetric Market Preferences}

In this section we investigate technologies that are asymmetric in market preference. We adopt a Bernoulli market preference distribution as opposed to the uniform distribution in the base model, which helps us manage the model complexity but also serves as a robustness check on the market preference distribution (we confirm that the base model's equilibrium structure remains qualitatively unchanged under the new distribution in the case of symmetric market preferences). To be specific, we assume that the market share that prefers technology $1, A$, follows a Bernoulli distribution that takes value 1 with probability $\alpha$ and 0 with probability $1-\alpha$, and that the market share that prefers technology 2 is $1-A$. In other words, the entire market either prefers $T_{1}$ or prefers $T_{2}$. Without loss of generality, we assume $\alpha \geq 1 / 2$. This means that $T_{1}$ 's market share is stochastically larger than $T_{2}$ 's; thus, $M_{1}$ is the advantaged manufacturer. The detailed analysis can be found in Supplement $C$ in the online appendix; we illustrate only the stage 1 and 2 equilibrium outcomes with varying $\alpha$ and $K$ for $\gamma=1 / 2$ in Figure 7. The notation is the same as in Figure 6. In addition, Figure S2 in Supplement $C$ in the online appendix illustrates equilibrium outcomes with other $\gamma$ values, which have similar structures as Figure 7.

We list some notable observations about Figure 7. We omit detailed explanations for the observations that mirror those about Figure 6. 
Figure 7. Equilibrium Outcomes Under Asymmetric Market Sizes

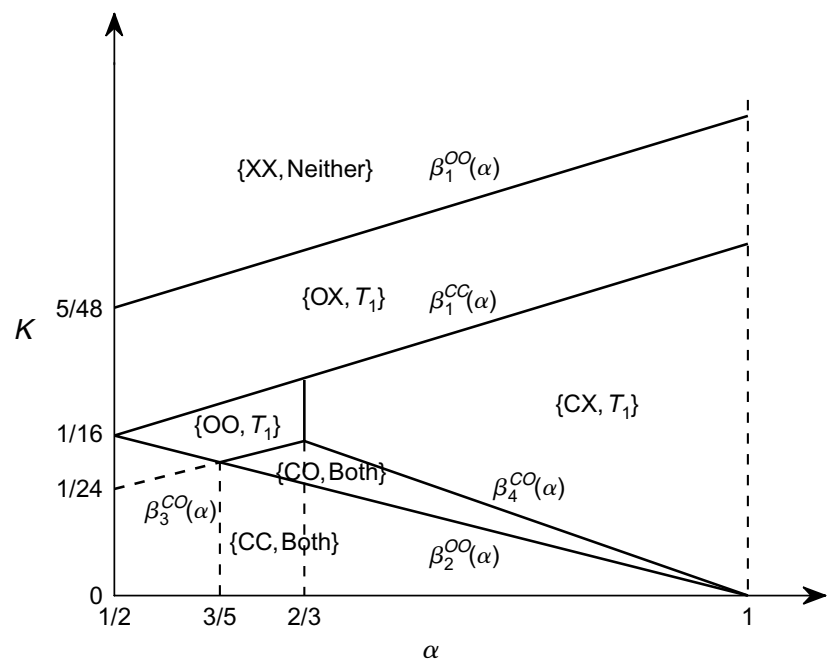

First, asymmetric equilibria may arise, and in most cases the disadvantaged manufacturer 2 opens his technology.

Second, on the one hand, the advantaged manufacturer 1 opens his technology when the investment cost is high (equilibrium $\left\{\mathrm{OX}, T_{1}\right\}$ ). On the other hand, as the investment cost decreases, manufacturer 1 tends to close his technology. Moreover, as the disparity between the manufacturers becomes larger, i.e., $\alpha$ increases, manufacturer 1 is more likely to close his technology, whereas the supplier tends to invest only in the advantaged technology 1 , regardless of manufacturer 2's technology strategy (equilibrium $\left\{C X, T_{1}\right\}$ ).

Third, the disadvantaged manufacturer may force his competitor to open his technology by opening his own technology. Consider the region with equilibrium $\left\{\mathrm{OO}, T_{1}\right\}$, where the investment cost is moderate and the disparity between manufacturers is small. In such cases, the supplier always invests in only one technology. If manufacturer 2 closed his technology, so would manufacturer 1 , to deter competition, resulting in manufacturer 2 exiting the market. However, if manufacturer 2 opens $T_{2}$, manufacturer 1 is forced to open $T_{1}$ as well; otherwise, the supplier will only invest in $T_{2}$, which reduces manufacturer 1's profit.

To summarize, the extensions to asymmetric technologies, either in investment cost or in market preference, reveal highly consistent insights. First, the base model's equilibrium behaviors are robust under nottoo-significant technology asymmetry. Second, asymmetric technologies may lead to asymmetric equilibria, where in most cases the disadvantaged manufacturer opens his technology.

\subsection{Alternative Source of Supply}

In this section, we assume that there is an exogenous alternative source of supply for both technologies with a fixed wholesale price $s>0$ and unlimited capacity, for example, an existing market for the critical components. Recall that the focal supplier considered in the base model can make an investment to gain the capability to economically supply for each technology, thereby achieving a marginal cost advantage over the outside supplier. What is different now is that even when the focal supplier does not invest in a particular technology, a manufacturer still has the option of obtaining the critical components for his technology from the alternative source at a cost premium. This extension captures the situations where without significant investments to bring down component costs, the technologies can still serve some premium customers.

The sequence of events is the same as for the base model, with the modification that in stage 4, the manufacturers now have access to an alternative source. The detailed analysis can be found in Supplement D in the online appendix; we illustrate only the stages 1 and 2 equilibria in Figure 8 for $s \in[1 / 2,2 / 3]$.

We make a few observations about Figure 8. First, when the alternative source is expensive, for all levels of investment costs, the equilibrium structure is consistent with the base model. For example, when $s$ is close to $2 / 3$, we recover the equilibrium structure of the base model for $\gamma=1 / 2$ (see Figure 3). Even when the alternative source is not very expensive, as long as the investment cost $K$ is sufficiently low, the base model's equilibrium behaviors are recovered. Therefore, the base model's equilibrium behaviors are robust for relatively expensive alternative sources of supply.

Second, as the alternative source becomes more affordable, the high-investment-cost region where the supplier invests in neither technology expands. This is because the affordable alternative source makes it more difficult for the focal supplier to serve

Figure 8. Optimal Decisions Under Alternative Sourcing

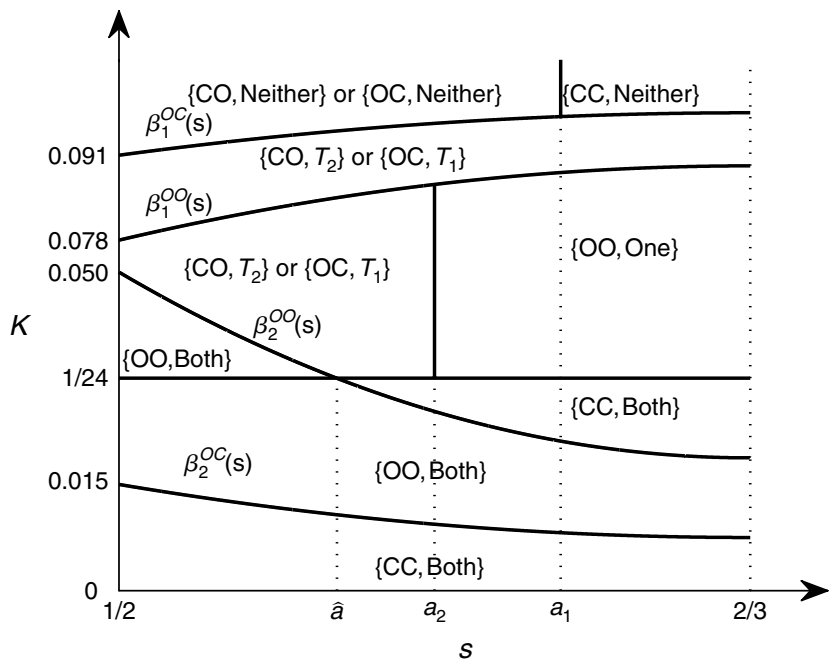

Note. $a_{1} \approx 0.661, a_{2} \approx 0.633$, and $\hat{a} \approx 0.596$. 
the manufacturers profitably. On the other hand, the low-investment-cost region where the supplier invests in both technologies expands as well. This is because, faced with an affordable alternative source, the supplier needs to compete more aggressively for the manufacturers' business. Accordingly, the intermediate-investment-cost region where the supplier invests in only one technology shrinks.

Third, with an affordable alternative source, asymmetric equilibria arise between two symmetric manufacturers. More specifically, in the intermediateinvestment-cost region, asymmetric equilibria arise where one technology is open and the other is closed, and the supplier invests in the open technology. In these equilibria, the two manufacturers are faced with drastically different market environments and display different sourcing behaviors. For the manufacturer with the open technology, when the technology is popular he has to compete with the other manufacturer, but both can enjoy cheaper components provided by the focal supplier. For the manufacturer with the closed technology, when the technology is popular he can enjoy his own market share as a monopoly, but he has to depend on the alternative source of supply at a premium.

To summarize, the base model's equilibrium behaviors are robust with an expensive alternative source of supply. As the alternative source becomes more affordable, depending on whether the investment cost is high or low, the focal supplier may be more likely to give in to competition and invest in neither technology or compete more aggressively and invest in both technologies. Finally, the alternative supply source may induce asymmetric technology strategy equilibria between two symmetric manufacturers. It is worth noting though that while we have investigated the impact of an exogenous alternative source of supply, it remains to understand the impact of a strategic alternative supplier or a supply-side market.

\section{Conclusion and Future Research Directions}

Competing technologies are a common sight in emerging industries. They create technology uncertainties that discourage suppliers from making cost-reducing investments, slowing these industries' growth to their full potential. Motivated by the recent case of Tesla and Toyota opening their competing alternative-energy vehicle technologies, we study a model where two competing manufacturers that own proprietary technologies choose whether to open their technologies to each other. Based on the manufacturers' choices, a supplier then decides on whether she will invest in either technology, followed by the manufacturers' product technology choice and procurement endeavors. Our model captures the most salient elements of real-life manufacturers' open-technology considerations, including technology uncertainty, competitor response, supplier investment, and intensified competition after a technology proves popular.

We analyze the game and fully characterize its equilibria. The results confirm that firms' open-technology strategies may induce supplier investments but may also intensify future competition. Furthermore, the results reveal insights beyond our initial intuition. We show that in some cases, firms can close technologies to induce supplier investments. We also show that besides incentivizing supplier investments, open technologies have another benefit, namely, technology risk pooling. Finally, a prisoner's dilemma situation exists in which firms may choose to close their technologies despite the full risk-pooling benefits when both technologies are open. In this case, there is great potential for collaborative technology sharing through cross licensing. For a summary of the main insights, see Figure 1 in Section 1.

We then investigate several extensions and confirm the general robustness of our main insights. Additionally, we find that when two technologies are asymmetric, the disadvantaged firm is more likely to open its technology to influence the supplier's investment preference, and with an exogenous alternative source of supply, the supplier may be driven to invest more aggressively if the competition is weak, or may give in to competition and not make any investment if the competition is strong. These insights further enrich those obtained from the base model.

To our best knowledge, we are the first to investigate the supply-side implications of open technologies. Our analysis shows that firms' technology strategies give rise to rich vertical and horizontal interactions throughout and across supply chains, and it suggests that firms need to thoroughly understand open technologies' far-reaching impacts before deciding on their technology strategies. The insights revealed in this paper may help inform firms in such decisions. Moreover, our analysis may extend to other players in technology ecosystems. For example, when a consumer buys a car, he or she is actually buying a means of transportation, of which the charging/fueling network is also a "component." Therefore, an energy company considering building electricity charging or hydrogen fueling networks is akin to a supplier considering making investments into building components for electric or hydrogen fuel cell cars, and our analysis may also shed light on the impact of open technologies on charging/fueling network constructions.

There are a number of promising ways to further the research on open technologies. First, we model open technologies as being completely free for adoption, after the cases of Tesla and Toyota. For continuity, we do not expect small adoption costs to substantially alter 
our model's behaviors, whereas the impacts of significant adoption costs require future study. Another common way to share technology is through licensing, which makes a technology available but costly for adoption and transfers the cost back to the technology owner. Licensing bridges the extreme cases of completely closed and open technologies, and introduces a new lever that modulates both competition and revenue. Second, we consider each firm adopting only one technology, after the cases of Tesla and Toyota, but a firm can potentially adopt multiple technologies. This would likely make the open-technology strategy even more effective in inducing supplier investments, but more subtle insights can only be revealed by a rigorous study. Third, we model a single supplier investing in technologies, after the Tesla and Toyota case, but in other industries there may also be several oligopoly suppliers or many small suppliers, noncooperatively or cooperatively, making such investments. While we have investigated the impact of an exogenous alternative source of supply, it remains to understand the cases of multiple competing or cooperative strategic suppliers or a supply-side market. Fourth, we model strategic interactions between two manufacturers with proprietary technologies. In practice, there sometimes exist companies without proprietary technologies that will adopt open technologies. Such "free riders" would lead to potentially larger demands for the supply, which further incentivizes supplier investments in open technologies, but at the same time would also intensify future competition, which discourages manufacturers from opening proprietary technologies. It requires further rigorous analysis to determine which of these two effects dominates. Last, we intentionally assume away consumer-side network effects to isolate the supply-side effect, but it will be interesting to investigate the additional impact of consumer-side benefits. It is well understood that consumer-side network effects make consumers more likely to converge to one technology, and increase consumers' valuations of this technology, which should make firms more willing to open technologies. The impact on suppliers is, however, less obvious. On the one hand, the network effects should make suppliers more willing to invest in open technologies. On the other hand, since the market is more likely to converge to one technology, the supplier may invest in fewer technologies. These are all potential future research directions.

\section{Acknowledgments}

The authors thank Editor-in-Chief Christopher Tang, the associate editor, three anonymous reviewers, and Haresh Gurnani for their guidance and constructive comments.

\section{Endnotes}

${ }^{1}$ For example, electric cars have simpler structures and higher energy efficiency, whereas refueling hydrogen fuel cells is much faster than recharging batteries.

${ }^{2}$ This observation bears a similarity to the results of Goyal and Netessine (2007), who show that two competing manufacturers may both choose dedicated production technologies even if both manufacturers choosing flexible production technologies for their respective products leads to higher profits. On the other hand, we need to point out that despite the apparent similarity, the two dilemmas are in fact quite different. Our prisoner's dilemma is about two manufacturers not sharing their respective technologies with each other, whereas the prisoner's dilemma of Goyal and Netessine (2007) is about each of two manufacturers not using a flexible production technology for its own products.

\section{References}

Ayre J (2015a) Electric car demand growing, global market hits 740,000 units. Accessed November 15, 2015, http://cleantechnica .com/2015/03/28/ev-demand-growing-global-market-hits-740000 -units/.

Ayre J (2015b) Tesla Gigafactory and battery improvements could cut battery costs 50\%. Accessed November 15, 2015, http:// cleantechnica.com/2015/09/21/tesla-gigafactory-batteryimprovements-could-cut-battery-costs-70/.

Bessen J (2014) History backs up Tesla's patent sharing. Harvard Business Review (June 13), https://hbr.org/2014/06/history-backs -up-teslas-patent-sharing/.

Boyabatl $\mathrm{O}$ (2015) Supply management in multi product firms with fixed proportions technology. Management Sci. 61(12):3013-3031.

Boyabatl 1 O, Toktay LB (2011) Stochastic capacity investment and flexible vs. dedicated technology choice in imperfect capital markets. Management Sci. 57(12):2163-2179.

Boyabatl $\mathrm{O}$, Leng T, Toktay LB (2015) The impact of budget constraints on flexible vs. dedicated technology choice. Management Sci. 62(1):225-244.

Casadesus-Masanell R, Ghemawat P (2006) Dynamic mixed duopoly: A model motivated by Linux vs. windows. Management Sci. 52(7):1072-1084.

Casadesus-Masanell R, Llanes G (2011) Mixed source. Management Sci. 57(7):1212-1230.

Cole J (2014) Tesla battery in the Model S costs "less than a quarter" of the car in most cases. Accessed November 15, 2015, http://insideevs.com/tesla-battery-in-the-model-s-costs-lessthan-a-quarter-of-the-car-in-most-cases /.

Debo LG, Toktay LB, Van Wassenhove LN (2005) Market segmentation and product technology selection for remanufacturable products. Management Sci. 51(8):1193-1205.

Deign J (2015) Who is the world's biggest electric vehicle battery supplier? Accessed November 15, 2015, http://www. greentechmedia.com/articles/read/lg-chem-is-not-the-largest -auto-battery-supplier-in-the-world.

Economides N, Katsamakas E (2006) Two-sided competition of proprietary vs. open source technology platforms and the implications for the software industry. Management Sci. 52(7): 1057-1071

Edelstein S (2015) Tesla urges Japanese battery suppliers to take Gigafactory risk. Accessed November 15, 2015, http://www. greencarreports.com/news/1097507_tesla-urges-japanese-battery -suppliers-to-take-gigafactory-risk.

Erat S, Kavadias S (2006) Introduction of new technologies to competing industrial customers. Management Sci. 52(11):1675-1688.

Fellner WJ (1949) Competition Among the Few (Kelley, New York).

Gardner G (2015) Toyota launching fuel cell car Mirai. Portland Press Herald (October 4), http://www.pressherald.com/2015/10/04/ toyota-launching-fuel-cell-car-mirai/.

Goyal M, Netessine S (2007) Strategic technology choice and capacity investment under demand uncertainty. Management Sci. 53(2):192-207. 
Krishnan V, Bhattacharya S (2002) Technology selection and commitment in new product development: The role of uncertainty and design flexibility. Management Sci. 48(3):313-327.

Lerner J, Tirole J (2004) The economics of technology sharing: Open source and beyond. Working Paper 10956, National Bureau of Economic Research, Cambridge, MA.

Lyons C (2013) Research: 5 companies positioned to succeed in gridscale energy storage. Greentech Media (October 10), https://www .greentechmedia.com/articles/read/Research-5-CompaniesPostioned-to-Succeed-in-Grid-Scale-Energy-Storage.

Miller M (2011) Why the IBM PC had an open architecture. Accessed May 15, 2015, http://forwardthinking.pcmag.com/ pc-hardware/286065-why-the-ibm-pc-had-an-open-architecture.

Musk E (2014) All our patent are belong to you. http://www. teslamotors.com/blog/all-our-patent-are-belong-you.

Perkowski J (2014) Electric cars: A review of 2014. Forbes (December 12), http://www.forbes.com/sites/jackperkowski/2014/ 12/12/electric-cars-a-review-of-2014/.

Rogowsky M (2014) Blowing up: Tesla's Gigafactory is going to revolutionize the auto and utility industries. Forbes (February 26), http://www.forbes.com/sites/markrogowsky/2014/02/26/ blowing-up-teslas-gigafactory-is-going-to-revolutionize-the-auto -and-utility-industries/.
Spooner J, Kanellos M (2004) IBM sells PC group to Lenovo. Accessed May 15, 2015, http://news.cnet.com/IBM-sells-PCgroup-to-Lenovo/2100-1042_3-5482284.html.

Suarez F (2004) Battles for technological dominance: An integrative framework. Res. Policy 33(2):271-286.

Undercoffler D (2015) CES 2015: Toyota opens patents on hydrogen fuel cell technology. Los Angeles Times (January 5), http://www. latimes.com/business/autos/la-fi-hy-ces-2015-toyota-patent -hydrogen-fuel-cell-20150104-story.html.

Wang W, Ferguson ME, Hu S, Souza GC (2013) Dynamic capacity investment with two competing technologies. Manufacturing Service Oper. Management 15(4):616-629.

Watanabe C (2015) Ene-farms use hydrogen to power homes but don't come cheap. Bloomberg Business Week (January 19), http:// www.bloomberg.com/news/articles/2015-01-15/fuel-cells-for -homes-japanese-companies-pitch-clean-energy.

Weber S (2004) The Success of Open Source, Vol. 368 (Harvard University Press, Cambridge, MA).

Woodyard C (2015) Free fuel will help sell Toyota's fuel-cell car Mirai. USA Today (April 15), http://www.usatoday.com/story/ money/cars/2015/04/15/toyota-mirai-free-fuel-hydrogen/ $25805853 /$ 